\title{
AVALIAÇÃO DA DEMOCRACIA E VALORES SOCIAIS ENTRE JOVENS: O CASO DOS ESTUDANTES DA UNIVERSIDADE FEDERAL DO PARANÁ
}

\author{
Deivison Henrique de Freitas Santos ${ }^{1}$
}

\begin{abstract}
Resumo
Este artigo analisa qual é a opinião dos estudantes que ingressaram na Universidade Federal do Paraná, em 2018, sobre a situação da democracia no país, assim como o posicionamento do referido alunato sobre temas que geram controvérsias no debate público nacional, a saber, a descriminalização do aborto, a adoção de crianças por homossexuais e a proibição do comércio de armas de fogo e munição no país. Busca-se responder as seguintes indagações: (1) De que maneira os novos estudantes da UFPR avaliam a atual situação da democracia no Brasil? (2) Como os novos discentes se posicionam diante temas controversos? (3) Em que medida as posições assumidas pelos discentes se associam com variáveis individuais? Para o desenvolvimento da investigação, foi realizado um survey com uma parcela do novo alunato. No total, foram aplicados 474 questionários em estudantes de todos os cursos oferecidos pelas áreas de Ciências Humanas e Ciências Exatas da Universidade. O trabalho conta com o auxílio do software SPSS, utilizado para a promoção de estatísticas descritivas e de associação bivariada. Os resultados parciais indicam uma postura mais negativa entre os discentes analisados no que se refere à avaliação do regime democrático brasileiro. Sobre os temas controversos, o alunato se mostrou majoritariamente favorável às propostas. As análises estatísticas demonstram a existência de associações entre sexo e ideologia com as variáveis sobre democracia e valores sociais. Argumenta-se que estudos que privilegiam o comportamento da população jovem podem oferecer relevantes indícios sobre o futuro da democracia e das condições de vida de diferentes setores da sociedade.
\end{abstract}

Palavras-Chave: Cultura Política; Democracia; Valores Sociais; Estudantes; Survey.

\section{INTRODUÇÃ̃O ${ }^{2}$}

Muitos estudos no âmbito da Ciência Política têm se dedicado a compreender vários elementos associados à democracia e valores sociais em diversos países (INGLEHART; WELZEL, 2009; NORRIS; INGLEHART, 2019; PUTNAM, 2015). Ainda permanece central o debate sobre as mudanças enfrentadas por várias sociedades no que se refere tanto à dimensão institucional de suas democracias quanto aos seus aspectos culturais (ALMOND; VERBA, 1989; DAHL, 2015;

\footnotetext{
1 Mestrando do Programa de Pós-graduação em Ciência Política da Universidade Federal do Paraná. E-mail: deivisonfreitas@yahoo.com.br. ORCID: https://orcid.org/0000-0002-9257-8621.

${ }^{2} \mathrm{O}$ estudo em tela se trata de um recorte da monografia defendida pelo autor, em novembro de 2019 , no curso de Ciências Sociais da Universidade Federal do Paraná, intitulada: "Avaliação da democracia e valores sociais entre jovens: o caso dos estudantes de Ciências Humanas e Ciências Exatas da Universidade Federal do Paraná".
} 
INGLEHART; WELZEL, 2009; PRZEWORSKI; CHEIBUB; LIMONGI, 2003; PUTNAM, 2006).

No caso brasileiro não é diferente: há um conjunto de investigações que buscam entender as transformações nas práticas democráticas no país e os valores e condicionantes que levam a população a adotar uma postura favorável (ou não) ao regime democrático (BORBA, 2005; MOISÉS, 2010; MOISÉS; CARNEIRO, 2008).

Diante disso, torna-se relevante acompanhar a avaliação que parte da sociedade brasileira vem fazendo em relação à democracia no país - sobretudo tendo em vista os conflitos recentes da política nacional, a exemplo do impeachment de Dilma Rousseff (PT), em 2016, e as conturbadas relações envolvendo os três Poderes da República nos últimos anos. Estudos têm evidenciado que apreender de que forma as pessoas avaliam e se comportam frente às instituições e princípios democráticos pode servir como fator importante para o aperfeiçoamento do regime (INGLEHART; WELZEL, 2009; MOISÉS, 2010).

Nesse sentido, analisar, especificamente, o modo como a população mais jovem ${ }^{3}$ enxerga e avalia o regime democrático se mostra uma tarefa pertinente. Afinal, é justamente o foco sobre tal público que permite vislumbrar as possibilidades futuras para a manutenção do sistema (HOOGHE, 2004; SLOAM, 2016). Não obstante, o debate sobre determinadas controvérsias sociais como, por exemplo, a descriminalização do aborto, a adoção de crianças por casais do mesmo sexo e a proibição da venda de armas de fogo pode contribuir no processo de sistematização das características que marcam o Brasil contemporâneo, especialmente no que concerne ao tratamento de informações que também estão relacionadas com o ambiente democrático do país.

A juventude, então, encontra-se em posição de destaque quando consideradas as controvérsias sociais retratadas neste trabalho. Pesquisas indicam que, no Brasil, as mulheres jovens representam uma parcela significativa do grupo de pessoas que já passaram pelo procedimento do aborto em algum momento da vida (DINIZ; MEDEIROS; MADEIRO, 2016). Além disso, discussões ligadas à comunidade LGBTI+ têm recebido destaque em importantes trabalhos sobre mudanças culturais no campo da Ciência Política, evidenciando resultados especialmente relevantes acerca do público jovem em nações desenvolvidas (INGLEHART; WELZEL, 2009; NORRIS; INGLEHART, 2019). Por fim, hoje, no país, as principais vítimas de armas de fogo são jovens com até 29 anos, geralmente indivíduos pertencentes a camadas mais desfavorecidas da população (WAISELFSZ, 2016).

Isto posto, este artigo analisa qual é a opinião dos estudantes que ingressaram na Universidade Federal do Paraná (UFPR), em 2018, sobre a situação da democracia no país, assim como o

\footnotetext{
${ }^{3} \mathrm{~A}$ amostra que fundamenta este artigo se refere a indivíduos que, em média, possuem 21 anos. 
posicionamento do referido alunato sobre temas que geram controvérsias no debate público nacional, a saber, a descriminalização do aborto, a adoção de crianças por homossexuais e a proibição do comércio de armas de fogo e munição. Busca-se responder as seguintes indagações: 1) De que maneira os novos estudantes da UFPR avaliam a atual situação da democracia no Brasil? 2) Como os novos discentes se posicionam diante temas controversos? 3) Em que medida as posições assumidas pelos discentes se associam com variáveis individuais?

Argumenta-se, também, que a perspectiva investigativa aqui proposta possibilita elaborar indagações acerca do quanto as opiniões de certos segmentos estão diretamente relacionadas com os princípios de tolerância e inclusão social (RIBEIRO; BORBA, 2019). Nessa linha, discussões que consideram aspectos ligados à condição de vida de estratos relevantes da população se colocam como atividades essenciais para se entender a realidade social brasileira e as particularidades contidas em sua democracia.

O trabalho está dividido da seguinte forma. Em um primeiro momento, há uma breve revisão da literatura destacando relevantes produções que se debruçam sobre o tema da democracia e valores sociais, sobretudo no que diz respeito à população jovem. A próxima seção descreve as estratégias metodológicas do estudo. A partir disso, apresenta-se os resultados desta investigação, seguidos da discussão e considerações finais da pesquisa.

\section{REVISÃO DA LITERATURA}

Desde a obra seminal de Almond e Verba (1989 [1963]), pesquisas no campo da Cultura Política têm se dedicado a compreender de que forma valores, crenças e conhecimentos sobre o sistema político de uma sociedade se relacionam com as instituições e com o desempenho do regime democrático (FUKS et al., 2016; MOISÉS, 2010; PUTNAM, 2015). Como interessado em tal vertente, Moisés (2008) se empenha em avaliar - dentre outros fatores - de que modo as experiências dos cidadãos com as instituições democráticas afetam suas atitudes políticas. Perspectiva similar, aliás, é utilizada para investigar a posição do público jovem nesse tema (RUSSO; AZZI; FAVERI, 2018).

Putnam (2006), por sua vez, apresenta um estudo sobre as alterações da democracia italiana em razão das transformações institucionais ocorridas a partir de meados de 1970 naquele país, avaliando as relações de mútuos efeitos entre aspectos culturais de tal sociedade com sua nova dimensão institucional. Não obstante, preocupado com o que considera como um declínio do capital 
social nos Estados Unidos, Putnam (2015) também discorre sobre como as mudanças de hábitos da sociedade estadunidense - bem como suas causas - estariam ocasionando um processo de desengajamento cívico e comprometimento dos valores democráticos, acima de tudo por conta do esvaziamento de instituições e organizações comunitárias no país.

Outros trabalhos, entretanto, oferecem uma perspectiva distinta da tese de que estaria ocorrendo um processo de significativo desengajamento cívico nas sociedades contemporâneas. Inglehart (1971) sustenta que, em sociedades industrialmente avançadas, os indivíduos tenderiam a possuir suas necessidades de sobrevivência mais extensamente atendidas, garantindo, desse modo, uma maior segurança econômica. A partir disso, em sociedades denominadas como "pós-industriais" (economicamente mais avançadas), ocorreria um processo de mudança cultural, de caráter intergeracional, no qual as pessoas - notadamente as mais jovens -, em vez de se aterem a valores “aquisitivos", passariam a declarar valores "pós-burgueses". Segundo o autor, estaria ocorrendo uma mudança gradual nas prioridades valorativas individuais em diferentes sociedades pelo mundo.

Diante desse contexto, em lugar de se identificarem com valores relativos à sobrevivência (como a defesa da ordem, do controle de preços e do respeito à autoridade), em democracias pósindustriais os valores de autoexpressão (como a defesa da liberdade de expressão e da participação política) teriam preponderância. Por conseguinte, os indivíduos mais jovens e pós-materialistas de certas sociedades, em especial, buscariam formas alternativas de representação e participação, pois não mais sentiriam suas necessidades atendidas pelas instituições tradicionais. É isso que os levariam, por exemplo, a buscar formas não-convencionais de ação política e de oposição às elites estabelecidas (INGLEHART, 1971; INGLEHART; WELZEL, 2009).

Em estudo posterior, Inglehart e Welzel (2009) confirmam tais teses. Um exemplo interessante para a presente pesquisa trata-se dos efeitos das mudanças culturais sobre o rearranjo de orientações entre as parcelas mais jovens de indivíduos. De acordo com os autores:

\footnotetext{
A mudança na direção do pós-materialismo, como o aumento da ação política de oposição às elites, [é componente] de uma mudança mais abrangente na direção de valores de autoexpressão, conformando nova forma às orientações referentes à autoridade, à política, aos papéis de gênero e as normas sexuais entre os públicos das sociedades pós-industriais. Os pós-materialistas e os jovens são notadamente mais tolerantes com a homossexualidade do que os materialistas e idosos, e isso é parte de um padrão difuso: a ascensão de normas humanísticas que valorizam a emancipação humana e a autoexpressão (INGLEHART; WELZEL, 2009, p.161).
}

A literatura internacional recente também tem dado especial destaque para estudos interessados em investigar os hábitos, práticas e valores da juventude em diversos países (ALLASTE; 
CAIRNS, 2016; ILIŠIN; GVOZDANOVIĆ; POTOČNIK, 2017; NORRIS, 2004; YUEN, 2018). Salgado, Vásquez e Yáñez (2019) investigam o grau de altruísmo entre jovens chilenos durante um experimento no qual diferentes grupos, caracterizados por variados níveis de cooperação, participam de jogos que instigam os participantes a tomar um conjunto de decisões morais, descobrindo que as características de cada grupo se relacionam com as condições de associação entre os integrantes.

No âmbito nacional, Ribeiro (2008) analisa a teoria de Ronald Inglehart citada acima e chega a conclusões que diferem o caso brasileiro da tese original. Em seu estudo, elaborado a partir dos dados do Worlds Values Survey de 1991 e 1997, o autor identifica que os poucos pósmaterialistas brasileiros são mais propensos a participar de instituições tradicionais como partidos políticos, indo, em certa medida, de encontro à tese de que esse recorte da sociedade tenderia a ter uma posição de contestação às elites e as formas convencionais de participação.

Ainda no Brasil, diferentes pesquisas têm colocado o público jovem no centro das discussões (BAQUERO; BAQUERO, 2007; FUKS, 2012; OKADO; RIBEIRO, 2015; OLIVEIRA et al., 2016). Fuks e Casalescchi (2016) analisam os efeitos do programa Parlamento Jovem da Assembleia Legislativa de Minas Gerais. Os autores concluem que a participação em tal atividade garante um efeito positivo em diferentes dimensões, por exemplo, na promoção do conhecimento político, na confiança institucional e na tolerância às minorias. Telles (2010) ressalta as percepções de jovens entrevistados durante as eleições de 2010 em Belo Horizonte sobre um conjunto de aspectos ligados ao universo eleitoral à época. A autora deixa clara a importância que essa camada social vem ganhando nos últimos anos na política brasileira e realça a necessidade da expansão dos estudos que visem melhor compreender esse público. Tal defesa fica evidente já no título de seu trabalho: Jovens eleitores: decifra-me ou eu te devoro.

Entender de que forma uma parcela dos jovens universitários brasileiros pensam questões vinculadas ao sistema político e a temas polêmicos é uma providência de suma importância para o aperfeiçoamento das abordagens que buscam compreender os padrões comportamentais e as percepções sociais desse segmento - em consonância com trabalhos recentes que reconhecem a relevância de tal grupo quanto a questões ligadas, por exemplo, às mudanças climáticas ou à justiça social (CORNER et al., 2015; YUEN, 2018). Portanto, o presente estudo busca se inserir nesse campo de investigações, em um esforço para contribuir não somente para o melhor entendimento das dinâmicas e práticas por trás dos valores e hábitos que circundam o regime democrático como, também, com o intuito de oferecer informações sobre um importante segmento social quando se fala do processo de aperfeiçoamento e consolidação das instituições e valores democráticos: a juventude. 


\section{MATERIAIS E MÉTODOS}

\subsection{MÉTODOS DE COLETA}

Para a realização do trabalho, são utilizadas 474 entrevistas conduzidas pela Pólis Consultoria Política ${ }^{4}$ com o novo alunato dos setores de Ciências Humanas e Ciências Exatas da UFPR ao longo de 2018. O survey foi dividido em três blocos interessados em investigar, em um primeiro momento, as características sociodemográficas e econômicas dos entrevistados. Em seguida, foram selecionadas questões de cunho político-ideológico com o objetivo de captar as opiniões dos indivíduos acerca de temáticas ligadas à democracia e assuntos que geram polêmicas. No último bloco, buscou-se apreender a identificação político-partidária dos discentes 5 .

As entrevistas ocorreram entre o final do primeiro semestre de 2018 (maio/junho) e início do segundo semestre do mesmo ano (agosto/setembro). A aplicação dos questionários ficou a cargo de oito membros da equipe da empresa, incluindo o autor deste artigo. Antes do início da aplicação, houve um processo de discussão e avaliação interna do questionário, seguidos por um teste preliminar. A Tabela 1 apresenta o número de entrevistas aplicadas por setor e curso da universidade.

\section{TABELA 1 - NÚMERO DE ENTREVISTAS REALIZADAS POR SETOR E CURSO}

\begin{tabular}{lc|lc}
\hline \multicolumn{2}{c|}{ Setor de Ciências Humanas } & \multicolumn{2}{c}{ Setor de Ciências Exatas } \\
\hline \multicolumn{1}{c|}{ Curso } & N de entrevistas & \multicolumn{1}{c}{ Curso } & N de entrevistas \\
\hline Ciências Sociais & 29 & Física & 46 \\
Filosofia & 33 & Expressão Gráfica & 15 \\
História & 56 & Química & 32 \\
Psicologia & 27 & Ciência da Computação & 26 \\
Letras & 71 & Matemática & 62 \\
Turismo & 14 & Matemática Industrial & 17 \\
- & - & Estatística & $40^{6}$ \\
- & - & Informação Biomédica & 6 \\
\hline \multicolumn{2}{c|}{ Total } & 230 & \multicolumn{2}{c}{ Total } \\
\hline
\end{tabular}

FONTE: Elaboração própria, a partir dos dados coletados pela Pólis (2019).

\footnotetext{
4 A Pólis - Empresa Júnior de Consultoria Política é a EJ do curso de Ciências Sociais da UFPR, fundada em 2014, por estudantes vinculados à habilitação em Ciência Política. Seus trabalhos abrangem desde a realização de sondagens de opinião até o desenvolvimento de pesquisas de cunho puramente qualitativo. Para mais informações, ver: <https://www.facebook.com/polisufpr>. Para contato: polisempresajr@gmail.com. 5 Para mais informações sobre o questionário utilizado na pesquisa e sobre resultados adicionais do estudo, ver: <http://www.ponte.ufpr.br/dados/monodemocraciaevalores/>.

${ }^{6}$ No caso específico do curso de Estatística, os estudantes foram instruídos por dois integrantes da empresa a responderem às perguntas diretamente no questionário.
} 
Os dois setores elencados acima estão entre as áreas que mais ofereceram vagas no vestibular 2017/2018 da universidade em questão ${ }^{7}$. Aliás, avaliar a percepção dos discentes assim que entram na universidade pode ser uma maneira de evitar eventuais efeitos que a experiência universitária pode exercer sobre o alunato, permitindo a futuros estudos a realização de comparações entre os momentos de início e final desta trajetória. Por fim, pode-se considerar que a presente pesquisa se aproxima de um quase-experimento, podendo ensejar futuras investigações com o público jovem, semelhantemente a outros trabalhos nessa seara (FUKS; CASALESCCHI, 2016).

\subsection{MÉTODOS DE ANÁLISE}

A avaliação dos dados foi desenvolvida com o auxílio do software SPSS, utilizado para a realização das análises descritivas e para o desenvolvimento de testes de correlação bivariada rho de Spearman $^{8}$ (CERVI, 2019; FIELD, 2009). As variáveis dependentes do estudo são representadas pelas seguintes perguntas do questionário: (1) Considerando uma escala de 1 a 10, pedimos para que você avalie o quão democrático é o Brasil, tendo em mente que o 1 quer dizer "não democrático" e 10 quer dizer "totalmente democrático"; (2) Qual a sua opinião acerca da descriminalização do aborto? (1=a favor $\mid 2=$ contra); (3) Qual o seu posicionamento sobre a adoção de crianças por casais homoafetivos? (1=a favor $\mid 2=$ contra); e (4) Em sua opinião, o comércio de arma de fogo e munição deve ser proibido no Brasil? $(1=$ sim, deve ser proibido $\mid 2=$ não deve ser proibido $)$.

Todas as variáveis elencadas acima sofreram um processo de recodificação. Em primeiro lugar, alterou-se a variável sobre avaliação da democracia. As respostas 1, 2 e 3 foram agrupadas e nomeadas como "Pouco democrático"; as respostas 4 e 5 passaram pelo mesmo procedimento e foram nomeadas como "Moderadamente democrático"; as categoriais 6 e 7 ficaram como "Democrático"; e, finalmente, os respondentes que optaram pelas opções 8,9 ou 10 foram agrupados em uma nova categoria nomeada como "Muito democrático". Os códigos, então, passaram a ser: 1 para "Pouco democrático", 2 para "Moderadamente democrático", 3 para "Democrático", e 4 para "Muito democrático". Ou seja, quanto maior $o$ valor da categoria, mais positiva a avaliação sobre a

8 Também foram empreendidos outros testes de correlação, como aqueles indicados para variáveis dicotômicas. Entretanto, as saídas indicavam basicamente os mesmos resultados. Para fins de simplificação, optou-se por adotar o mesmo método para todos os cruzamentos. 
democracia no Brasil. As variáveis sobre a descriminalização do aborto, adoção de crianças por casais homossexuais e proibição de armas fogo também tiveram seus sinais alterados para $0=$ contra| $1=$ favor.

As variáveis independentes utilizadas nos referidos testes de correlação foram: escolaridade da mãe; escolaridade do pai; sexo; posicionamento ideológico; renda e tipo de escola em que cursou o ensino médio. Os enunciados de cada variável independente estão disponíveis no link para o questionário destacado anteriormente. Para o presente estudo, as variáveis independentes foram codificadas como: escolaridade da mãe $(0=$ sem ensino superior $\mid 1=$ com ensino superior $)$; escolaridade do pai $(0=$ sem ensino superior $\mid 1=\mathrm{com}$ ensino superior $)$; sexo $(0=$ feminino $\mid 1=$ masculino $)$; posicionamento ideológico $(0=$ esquerda $\mid 1=$ centro $\mid 2=$ direita $)$; e tipo de escola em que cursou o ensino médio $(0=$ maior parte ou integralmente particular|1=maior parte ou integralmente pública) ${ }^{9}$.

O processo de recodificação das variáveis mencionado até aqui foi realizado visando a facilitação dos testes do presente estudo e de futuras investigações com a mesma base de dados. Não obstante, as variáveis foram selecionadas tendo em vista não somente os objetivos da proposta, mas, também, pesquisas anteriores que demonstram a relevância de variáveis tais quais escolaridade, sexo, posicionamento ideológico, renda e convivência escolar no que diz respeito às opiniões de certas camadas da sociedade sobre diversos temas que permeiam o debate público (BAQUERO; BAQUERO, 2007; DEL PORTO, 2016; FUKS, 2011, 2012; FUKS; CASALESCCHI, 2018; MOISÉS; CARNEIRO, 2008; NORRIS; INGLEHART, 2019; RIBEIRO; BORBA, 2019). Por fim, mais do que promover uma análise robusta dos dados visando a testagem de hipóteses específicas, busca-se oferecer um panorama sobre o caso dos universitários da UFPR panorama que se pretende aprofundar em futuras versões do artigo em tela.

\section{RESULTADOS}

O Gráfico 1 apresenta a avaliação da democracia no Brasil feita pelos estudantes entrevistados na pesquisa. Percebe-se que a maioria dos discentes analisa a atual situação do regime no país como sendo "Moderadamente democrático" ou "Democrático", com 36,11\% e 33,12\% das respostas,

\footnotetext{
${ }^{9}$ A variável sobre a renda dos entrevistados foi mantida na sua forma original, que é: Somando a sua renda com a renda das pessoas que moram com você, quanto é, aproximadamente, a renda familiar mensal? 1 . Até 1 salário mínimo (até $R \$ 954,00) \mid 2$ 2. De 1 a 3 salários mínimos (de $R \$ 954,01$ até $R \$ 2.862,00) \mid$ 3. De 3 a 6 salários mínimos (de $R \$ 2.862,01$ até $R \$ 5.724,00) \mid 4$. De 6 a 9 salários mínimos (de $R \$ 5.724,01$ até $R \$ 8.586,00) \mid 5$. De 9 a 12 salários mínimos (de $R \$ 8.586,01$ até $R \$ 11.448,00$ ) | 6. De 12 a 15 salários mínimos (de $R \$ 11.448,01$ até $R \$$ 14.310,00)| 7. Mais de 15 salários mínimos (mais de $R \$ 14.310,01$ ).
} 
respectivamente. Em se tratando das demais opções, 20,73\% dos entrevistados acionaram a categoria "Pouco democrático", enquanto 10,04\% optaram pela categoria "Muito democrático". No geral, destaca-se que a maior parte do alunato avalia a situação da democracia no Brasil de forma negativa. Juntando as duas primeiras categoriais, nota-se que aproximadamente $60 \%$ dos discentes avaliam o regime como pouco ou moderadamente democrático.

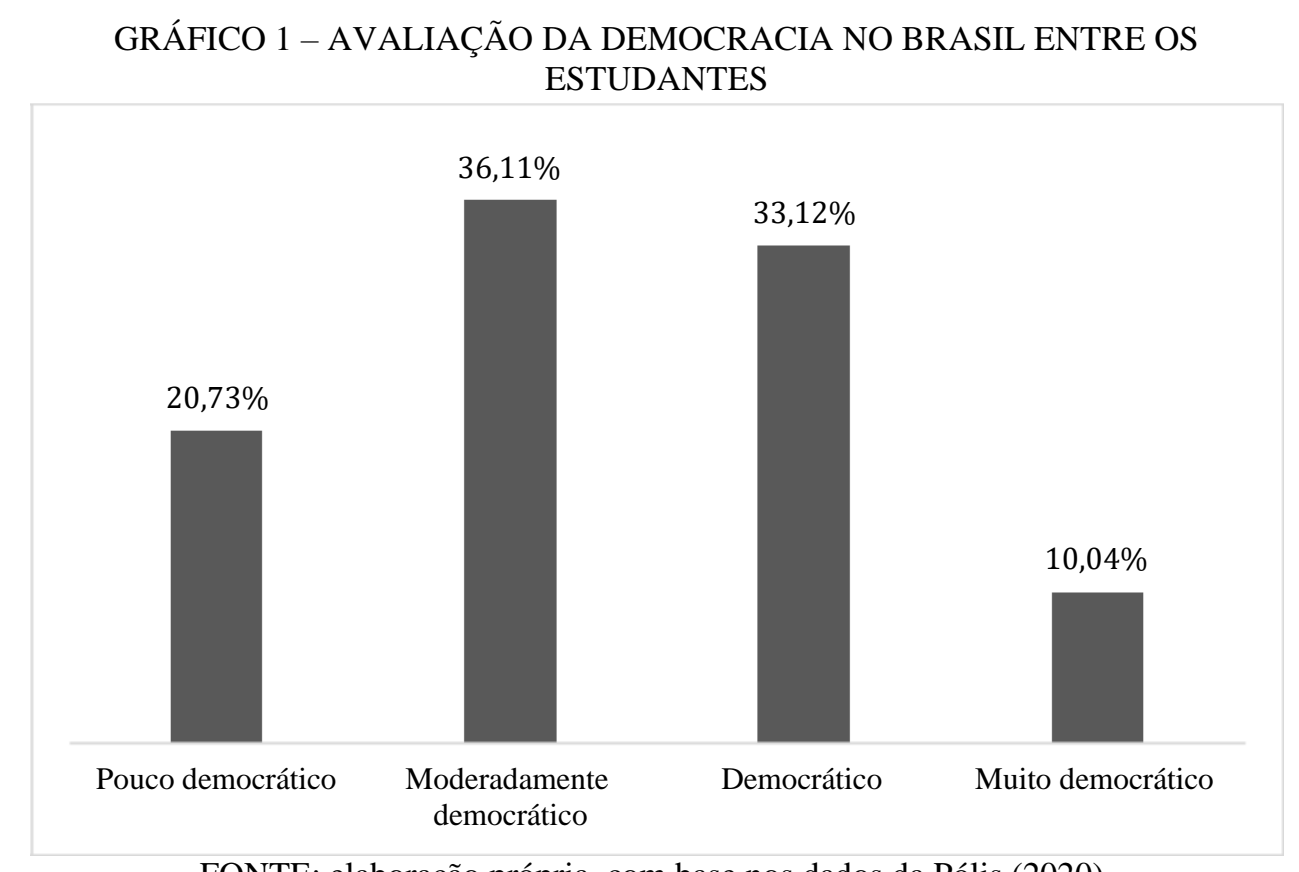

FONTE: elaboração própria, com base nos dados da Pólis (2020).

No que se refere às variáveis sobre temas que geram controvérsias no debate público do país, identifica-se que a maior parte dos respondentes se mostram adeptos a todas as medidas propostas. Sobre a descriminalização do aborto, $82,74 \%$ dos entrevistados disseram ser favoráveis à proposição, enquanto somente $17,26 \%$ adotaram uma postura mais resistente em relação à medida. Tratando-se da adoção de crianças por casais do mesmo sexo, $94,19 \%$ do alunato se mostrou favorável a tal possibilidade. Nesse caso, somente $5,81 \%$ dos discentes foram contrários à medida, o que demonstra uma ampla aceitação dos estudantes entrevistados quanto a adoção de crianças por casais LGBTI+. Por fim, o comportamento dos entrevistados acerca da proibição do comércio de armas de fogo e munição vai ao encontro dos resultados da primeira variável deste conjunto. Enquanto 81,08\% dos discentes foram favoráveis à proibição, apenas 18,92 apresentaram posturas mais resistentes à medida. 


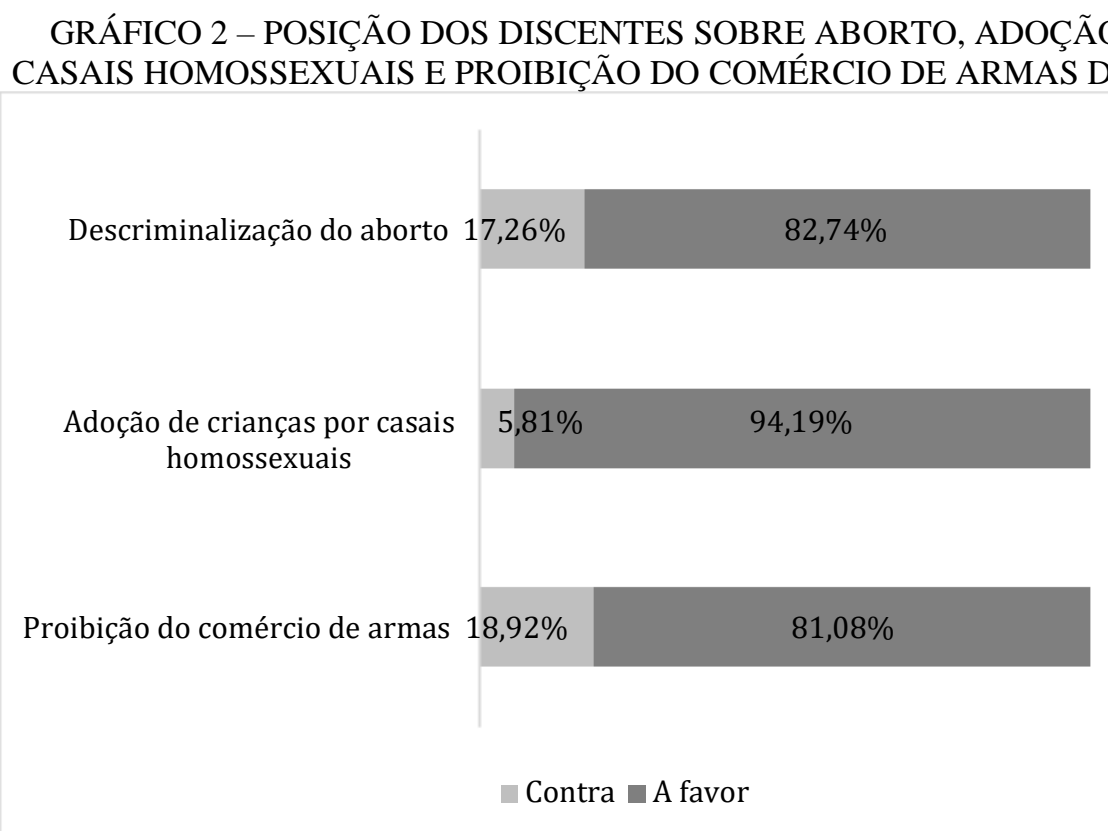

FONTE: Elaboração própria, com base nos dados da Pólis (2020).

A Tabela 2 evidencia os resultados dos testes de associação entre as variáveis dependentes e independentes do estudo. Vale salientar que são destacados somente os resultados que se mostraram estatisticamente significativos. Longe de querer propor uma análise estatística robusta, pretende-se demonstrar alguns elementos adicionais que impactam nas posições adotadas pelos discentes investigados. Os dados indicam que, na maioria das vezes, a escolaridade dos pais não se mostra variável relevante. Porém, especificamente no cruzamento entre escolaridade da mãe e avaliação da democracia, encontra-se correlação estatisticamente significativa ( $\mathrm{p}=0,021)$ e negativa, demonstrando que discentes com mães que possuem ensino superior tendem a avaliar a atual situação do regime democrático no Brasil de forma mais negativa. Entretanto, o coeficiente da correlação é muito baixo, de apenas $-0,10$.

Ainda sobre a avaliação da democracia entre os discentes, percebe-se que a variável sobre o sexo também se mostrou estatisticamente significativa $(\mathrm{p}=0,001)$ e positiva, indicando que pessoas do sexo masculino tendem a avaliar a situação da democracia no país de forma mais positiva. No entanto, uma vez mais, o coeficiente de correlação é muito baixo $(0,15)$. As outras duas variáveis estatisticamente significativas são: ideologia $(\mathrm{p}=0,000)$ e tipo de escola em que cursou ensino médio $(\mathrm{p}=0,043)$. No caso da primeira, que possui um coeficiente um pouco mais expressivo que as demais $(0,27)$, nota-se que respondentes que se posicionam mais à direita na escala de posicionamento ideológico apresentam avaliações mais positivas sobre a situação da democracia no país (ao mesmo tempo em que os estudantes que se posicionaram à esquerda avaliam o regime mais negativamente). 
A variável sobre tipo de escola aponta que estudantes que cursaram o ensino médio em escola pública tendem a avaliar a situação da democracia também de forma mais positiva - todavia, o coeficiente, novamente, mostrou-se muito baixo $(0,09)$.

TABELA 2 - CORRELAÇÕES ENTRE VARIÁVEIS INDIVIDUAIS E OPINIÃO DOS DISCENTES SOBRE A
DEMOCRACIA NO BRASIL E SOBRE TEMAS CONTROVERSOS

FONTE: Elaboração própria, com base nos dados da Pólis (2020).

$$
* \mathrm{p}<0,05 \mid * * \mathrm{p}<0,01
$$

Em se tratando da opinião dos discentes sobre a descriminalização do aborto, identifica-se que respondentes do sexo feminino tendem a se mostrar mais favoráveis a referida proposição, o mesmo ocorre com entrevistados que se posicionaram mais à esquerda na escala do espectro ideológico. Em ambos os casos os resultados se mostraram estatisticamente significativo ( $p=0,000)$, porém o único coeficiente mais expressivo foi aquele relacionado ao posicionamento ideológico (0,32) - mas ainda assim apontando uma baixa associação. No caso da adoção de crianças por casais do mesmo sexo, percebe-se que indivíduos mais à esquerda do espectro ideológico evidenciaram posturas mais favoráveis, mesmo o coeficiente de correlação sobre ideologia tendo apresentado um valor considerado muito baixo $(-0,18)$ - embora seja estatisticamente significativo em um nível bastante exigente $(\mathrm{p}=0,000)$.

Por fim, no que diz respeito à proibição do comércio de armas de fogo e munição, os achados apresentam que estudantes do sexo feminino se posicionaram mais favoravelmente à medida $(-0,25 \mid \mathrm{p}=0,000)$. Comportamento similar é encontrado entre os estudantes que pertencem a camadas de menor renda $(-0,10 \mid \mathrm{p}=0,040)$. A variável sobre o posicionamento ideológico acentua que respondentes que se posicionam mais à esquerda tendem a apoiar a proibição do comércio de armas de fogo e munição no país $(-0,32 \mid$ p=0,000). A próxima seção do trabalho propõe uma breve discussão sobre os achados e encerra a investigação em tela. 


\section{DISCUSSÃO E CONSIDERAÇÕES FINAIS}

Antes de qualquer reflexão, é importante destacar que as informações discutidas até aqui se relacionam com os estudantes que ingressaram à Universidade no ano de 2018 em dois setores específicos, Ciências Humanas e Ciências Exatas. Logo, não é possível fazer afirmações sobre todos os discentes dos setores investigados, muito menos sobre o corpo estudantil da Universidade como um todo. Além disso, ao contemplar somente estudantes universitários há, de antemão, um recorte específico na pesquisa, visto que tal grupo representa uma pequena e privilegiada camada da juventude brasileira ${ }^{10}$. Dito isso, alguns resultados despertam maior interesse para a discussão.

As associações entre escolaridade da mãe, posicionamento ideológico, sexo e avaliação da democracia no Brasil ensejam algumas reflexões. No caso da escolaridade dos pais, a associação encontrada entre a escolaridade da mãe e a avaliação da democracia é muito baixa e, quando se separa os setores, ela se torna insignificante nos dois casos. Acredita-se que, na prática, o efeito da escolaridade dos pais não se caracteriza com um aspecto muito relevante entre os respondentes da pesquisa. Comportamento similar é identificado no caso do sexo dos respondentes ${ }^{11}$.

Entretanto, tratando-se da variável sobre o posicionamento ideológico dos discentes, percebe-se que há uma relação mais expressiva entre se posicionar mais à esquerda no espectro ideológico e apresentar posturas mais críticas em relação à atual situação da democracia no país. Tal resultado pode estar relacionado com o contexto político brasileiro, que durante a realização da pesquisa já enfrentava um período conturbado há alguns anos (LIMONGI; FIGUEIREDO, 2017). O impeachment de Dilma Rousseff, em 2016, foi uma derrota para alas à esquerda da política nacional, visto que o Partido dos Trabalhadores ocupava o posto mais alto da República há mais de 13 anos. Não obstante, a maneira como o processo se deu gerou debates acerca da legitimidade do afastamento de Dilma do poder (AMORIM NETO, 2016; SANTOS; GUARNIERI, 2016) - ao mesmo tempo em que as decisões e medidas aprovadas pelo seu sucessor, Michel Temer (Movimento Democrático Brasileiro), também foram motivo de contestação por parte de alguns segmentos da sociedade ${ }^{12}$.

No tocante aos temas controversos, nota-se que, em todos os casos, ser de esquerda está associado a uma postura mais favorável às medidas. Esse resultado não surpreende, afinal essas são

10 Atualmente, apenas $18 \%$ dos jovens em idade universitária no Brasil, de fato, estão em uma universidade. Disponível em: <https://www1.folha.uol.com.br/educacao/2018/09/ensino-superior-volta-a-crescer-no-pais-mas-so-namodalidade-a-distancia.shtml>. Acesso em: 26 jun. 2020.

11 Informações adicionais sobre os testes empregados entre os setores podem ser consultados no link: <http://www.ponte.ufpr.br/dados/monodemocraciaevalores/>.

12 Disponível em: <http://g1.globo.com/politica/noticia/2016/09/estados-tem-protestos-contra-michel-temer-no-7-desetembro.html $>$. Acesso em: 26 de jun. 2020. 
bandeiras defendidas por vários movimentos e partidos mais à esquerda da política nacional apesar de não serem os únicos. Em se tratando especificamente da descriminalização do aborto e da proibição do comércio de armas, os dados indicam que o sexo do respondente se apresenta como variável relevante, sendo que mulheres são mais favoráveis as duas proposições. Possivelmente, isso se justifica pelo fato de que são elas as mais afetadas no caso do aborto (DINIZ; MEDEIROS; MADEIRO, 2016) e, além disso, também fazem parte do grupo da população que, frequentemente,

é exposto a vários tipos de violência, inclusive aqueles que envolvem o uso de armas de fogo ${ }^{13}$ - o mesmo pode ser dito das parcelas de menor renda da sociedade (WAISELFSZ, 2016). Mesmo assim, são necessárias mais investigações para aprofundar o debate sobre tais assuntos.

De forma geral, os achados indicam que, dentre os jovens entrevistados na pesquisa, a maior parte não somente adota posturas mais críticas em relação à situação da democracia no país como, ademais, demonstram posturas favoráveis a todas as dimensões propostas no estudo. Como já destacado, por exemplo, a adoção de crianças por casais homoafetivos é aceita por uma expressiva maioria dos respondentes, superando os índices de 90\% (isso também se repete quando os setores são analisados separadamente). O modo favorável com o qual os estudantes se posicionam acerca de tal proposição pode denotar atitude tolerante quanto às minorias sexuais do país. Tal aspecto, aliás, está em consonância com estudos já consagrados no campo da Ciência Política que demonstram que o público jovem, em especial em nações desenvolvida, tende a adotar posturas mais liberais em vários aspectos da vida em sociedade, inclusive naqueles que envolvem a comunidade LGBTI+ (INGLEHART; WELZEL, 2009; NORRIS; INGLEHART, 2019).

Futuras investigações podem expandir as indagações aqui propostas, incluindo novas variáveis na discussão, aprimorando as estratégias metodológicas e estendendo a pesquisa para outras camadas da juventude brasileira além daquela vinculada ao meio universitário - sobretudo tendo em vista a relevância desse público para o fortalecimento e manutenção do regime democrático (HOOGHE, 2004; SLOAM, 2016).

\section{REFERÊNCIAS}

ALLASTE, Airi-Alina; CAIRNS, David. Introduction: Youth Political Participation in a Transition Society. Studies of Transition States and Societies, vol. 8, n. 2, p. 1-9, 2016. 
ALMOND, Gabriel A.; VERBA, Sidney. The civic culture: political attitudes and democracy in five nations. Newbury Park: SAGE Publications, 1989.

AMORIM NETO, Octavio. A crise política brasileira de 2015-2016: Diagnóstico, sequelas e profilaxia. Relações Internacionais, n. 52, p. 43-54, Dezembro, 2016.

BAQUERO, Rute; BAQUERO, Marcelo. 2007. Educando para a Democracia: valores democráticos partilhados por jovens porto-alegrenses. Ciências Sociais em Perspectiva, vol. 6, n. 11, p. 139-143, $2^{\circ}$ semestre, 2007.

BORBA, Julian. Cultura Política, Ideologia e Comportamento Eleitoral: alguns apontamentos teóricos sobre o caso brasileiro. Opinião Pública, vol. 11, n. 1, p. 147-168, Março, 2005.

CERVI, Emerson Urizzi. Manual de Métodos Quantitativos para Iniciantes em Ciência Política - Vol. 2. Curitiba: CPOP - UFPR, 2019.

CORNER, Adam; ROBERTS, Olga; CHIARI, Sybille; VÖLLER, Sonja; MAYRHUBER, Elisabeth S.; MANDL, Sylvia; MONSON, Kate. How do young people engage with climate change? The role of knowledge, values, message framing, and trusted communicators. WIREs Clim Change, vol. 6, p. 523-534, 2015.

DAHL, Robert A. Poliarquia: participação e oposição. São Paulo: Editora da Universidade de São Paulo, 2015.

DEL PORTO, Fabíola Brigante. Satisfação com a democracia entre os brasileiros no cenário recente (2002-2014). Revista Debates, vol. 10, n. 3, p. 83-106, Setembro-dezembro, 2016.

DINIZ, Débora; MEDEIROS, Marcelo; MADEIRO, Alberto. Pesquisa Nacional de Aborto 2016.

Ciência \& Saúde Coletiva, vol. 22, n. 2, p. 653-660, 2017.

FIELD, Andy. Descobrindo a estatística usando o SPSS. Porto Alegre: Artmed, 2009.

FUKS, Mario. Efeitos diretos, indiretos e tardios: trajetórias da transmissão intergeracional da participação política. Lua Nova, n. 83, p. 145-178, 2011.

FUKS, Mario. Atitudes, cognição e participação política: padrões de influência dos ambientes de socialização sobre o perfil político dos jovens. Opinião Pública, vol. 18, n. 1, p. 88-108, Junho, 2012.

FUKS, Mario; CASALESCCHI, Gabriel Avila. Formando cidadãos democráticos: considerações sobre os efeitos do Parlamento Jovem mineiro. Cadernos Adenauer xvii, n. 1, p. 145-164, 2016.

FUKS, Mario; CASALESCCHI, Gabriel Avila; GONÇALVES, Guilherme Quaresma; DAVID, Flávia Felizardo. Qualificando a adesão a democracia: quão democráticos são os democratas brasileiros. Revista Brasileira de Ciência Política, n. 19, p. 199-219, Janeiro-abril, 2016.

FUKS, Mario; CASALESCCHI, Gabriel A. Expandindo o conceito de competência política: conhecimento político e atitudes democráticas na América Latina. Revista de Sociologia Política, vol. 26, n. 68, p. 61-74, Dezembro, 2018. 
HOOGHE, Marc. Political socialization and the future of politics. Acta Politica, vol. 39, n. 4, p. 331-341, December, 2004.

ILIŠIN, Vlasta; GVOZDANOVIĆ, Anja; POTOČNIK, Dunja. Contradictory tendencies in the political culture of Croatian youth: unexpected anomalies or an expected answer to the social crisis? Journal of Youth Studies, vol. 21, n. 1, p. 51-71, June, 2017.

INGLEHART, Ronald. The silent revolution in Europe: intergenerational changes in post-industrial societies. American Political Science Review, vol. 65, n. 4, p. 991-1017, December, 1971.

INGLEHART, Ronald; WELZEL, Christian. Modernização, Mudança Cultural e Democracia: a Sequência do Desenvolvimento Humano. São Paulo: Francis, 2009.

LIMONGI, Fernando; FIGUEIREDO, Argelina Cheibub. A crise atual e o debate institucional. Novos Estudos Cebrap, vol. 36, n. 3, p. 79-97, 2017.

MOISÉS, José Álvaro; CARNEIRO, Gabriela Piquet. Democracia, desconfiança política e insatisfação com o regime - o caso do Brasil. Opinião Pública, vol. 14, n. 1, p. 1-42, Junho, 2008.

MOISÉS, José Álvaro. Cultura política, instituições e democracia: Lições da experiência brasileira. Revista Brasileira de Ciências Sociais, vol. 23, n. 66, p. 11-43, Fevereiro, 2008.

MOISÉS, José Álvaro. Os significados da democracia segundo os brasileiros. Opinião Pública, vol. 16, n. 2, p. 269-309, Novembro, 2010.

NORRIS, Pippa. Young People \& Political Activism: From the Politics of Loyalties to the Politics of Choice? Paper for the conference 'Civic engagement in the 21st Century: Toward a Scholarly and Practical Agenda' at the University of Southern California, October 1-2, 2004.

NORRIS, Pippa; INGLEHART, Ronald. Cultural backlash: Trump, Brexit and authoritarian populism. Cambridge: Cambridge University Press, 2019.

OKADO, Lucas Toshiaki Archangelo; RIBEIRO, Ednaldo Aparecido. Condição juvenil e participação política no Brasil. Paraná Eleitoral, vol. 4, n. 1, p. 53-78, 2015.

OLIVEIRA, Renata A. de; AYRES, Carla S.; HANSEN, Jaqueline Resmini; BORBA, Julian. Política e juventude: participação política dos jovens do Sul do Brasil. Revista Debates, vol. 10, n. 3, p. 189-222, Setembro-dezembro, 2016.

PRZEWORSKI, Adam; CHEIBUB, José Antônio; LIMONGI, Fernando. Democracia e cultura: uma visão não culturalista. Lua Nova, n. 58, p. 9-36, 2003.

PUTNAM, Robert. 2006. Comunidade e democracia: a experiência da Itália moderna. $5^{\circ}$ Ed. Rio de Janeiro: Editora FGV, 2006.

PUTNAM, Robert. Jogando boliche sozinho: colapso e ressurgimento da coletividade americana. Curitiba: Instituto Atuação, 2015. 
RIBEIRO, Ednaldo Aparecido. Pós-materialismo e participação política no Brasil. Sociedade e Cultura, vol. 11, n. 2, p. 375-387, Dezembro, 2008.

RIBEIRO, Ednaldo Aparecido; BORBA, Julian. Tolerância política no Brasil recente: evolução de indicadores e condicionantes. Caderno CRH, vol. 32, n. 87: 641-657, 2019.

RUSSO, Guilherme A.; AZZI, Roberta Gurgel; FAVERI, Charlene. Confiança nas instituições políticas: diferenças e interdependência nas opiniões de jovens e população brasileira. Opinião Pública, vol. 24, n. 2, p. 365-404, Maio-agosto, 2018.

SANTOS, Fabiano; GUARNIERI, Fernando. From Protest to Parliamentary Coup: An Overview of Brazil's Recent History. Journal of Latin American Cultural Studies, vol. 25, n 4, p. 485-494, 2016.

SLOAM, James. Diversity and voice: The political participation of young people in the European Union. The British Journal of Politics and International Relations, vol. 18 n. 3, p. 521-537, 2016.

TELLES, Helcimara. Jovens eleitores: decifra-me ou te devoro. Em Debate, vol. 2, n. 11, p. 22-27, Novembro, 2010.

WAISELFISZ, Julio J. Mapa da violência 2016: Homicídios por armas de fogo no Brasil. [S.1.]: Flacso, 2016.

YUEN, Celeste Y. M. Perceptions of Social Justice Among the South Asian and Mainstream Chinese Youth from Diverse Cultural Backgrounds in Hong Kong. Peabody Journal of Education, vol. 93, n. 3, p. 1-13, May, 2018. 